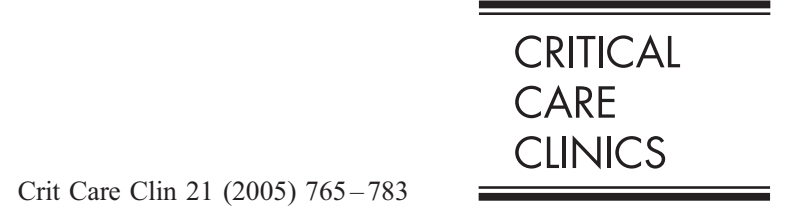

\title{
Hemorrhagic Fever Viruses
}

\author{
David C. Pigott, MD \\ Department of Emergency Medicine, The University of Alabama at Birmingham, \\ 619 South $19^{\text {th }}$ Street, Birmingham, AL 35249-7013, USA
}

Viral hemorrhagic fevers (VHF) are a group of febrile illnesses caused by RNA viruses from several viral families. They include species from the family of filoviruses (Ebola and Marburg), from the family of arenaviruses (Lassa and New World arenaviruses), from the family of bunyaviruses (Congo-Crimean Hemorrhagic Fever and Rift Valley Fever), and from the family of flaviviruses (yellow fever, among others). These highly infectious viruses lead to a potentially lethal disease syndrome characterized by fever, malaise, vomiting, mucosal and gastrointestinal (GI) bleeding, edema, and hypotension. The most notorious member of this group is the Ebola virus, which has been associated with case fatality rates of up to $90 \%$. These diseases are generally contracted via an infected animal or arthropod vector, although the natural reservoirs for some VHF, such as Ebola and Marburg, remain unknown (Table 1) [1].

In 2000, the Centers for Disease Control and Prevention (CDC) Strategic Planning Workgroup developed a system for categorizing potential agents of bioterrorism into Categories A, B, and C. Those agents in Category A are believed to pose the greatest threat to public health because of ease of dissemination or transmission, potential for high mortality, and significant impact on public health including panic, social, and economic disruption [2]. Along with infectious agents such as anthrax and smallpox, several VHF viruses are classified as Category A: Ebola, Marburg, Lassa, Junin, Machupo, Guanarito, and Sabia. This review will focus on those VHF agents that may represent the greatest threat of bioterrorism, although this should not suggest that other VHF agents could not be used as biological weapons.

The VHF viruses considered to have the greatest potential risk as biological warfare agents share certain characteristics: extreme pathogenicity, and potential

Figure Legends (please note: the figures and tables included with this work are from US Government publications and are in the public domain).

E-mail address: dpigott@uabmc.edu 
Recognized viral hemorrhagic fevers of humans

\begin{tabular}{|c|c|c|c|c|c|}
\hline \multirow[b]{2}{*}{ Virus family genus } & \multirow[b]{2}{*}{ Disease (virus) } & \multirow[b]{2}{*}{ Natural distribution } & \multicolumn{2}{|c|}{$\underline{\text { Source of human infection }}$} & \multirow[b]{2}{*}{ Incubation (days) } \\
\hline & & & Usual & Less likely & \\
\hline \multicolumn{6}{|l|}{ Arenaviridae } \\
\hline \multirow[t]{5}{*}{ Arenavirus } & Lassa fever & Africa & Rodent & Nosocomial & $5-16$ \\
\hline & Argentine HF (Junin) & South America & Rodent & Nosocomial & $7-14$ \\
\hline & Bolivian HF (Machupo) & South America & Rodent & Nosocomial & $9-15$ \\
\hline & Brazilian HF (Sabia) & South America & Rodent & Nosocomial & $7-14$ \\
\hline & Venezuelan HF (Guanarito) & South America & Rodent & Nosocomial & $7-14$ \\
\hline \multicolumn{6}{|l|}{ Bunyaviridae } \\
\hline Phlebovirus & Rift Valley fever & Africa & Mosquito & $\begin{array}{l}\text { Slaughter of } \\
\text { domestic animal }\end{array}$ & $2-15$ \\
\hline Nairovirus & Crimean-Congo HF & Europe, Asia, Africa & Tick & $\begin{array}{l}\text { Slaughter of } \\
\text { domestic animal; } \\
\text { nosocomial }\end{array}$ & $3-12$ \\
\hline Hantavirus & $\begin{array}{l}\text { HFRS (Hantaan and } \\
\text { related viruses) }\end{array}$ & $\begin{array}{l}\text { Asia, Europe; possible } \\
\text { worldwide }\end{array}$ & Rodent & & $9-35$ \\
\hline \multicolumn{6}{|l|}{ Filoviridae } \\
\hline Filovirus & Marburg and Ebola HF & Africa & Unknown & Nosocomial & $3-16$ \\
\hline \multicolumn{6}{|l|}{ Flaviviridae } \\
\hline \multicolumn{6}{|l|}{ Flavivirus } \\
\hline \multirow[t]{2}{*}{ (Mosquito-borne) } & Yellow fever & Tropical Africa, South America & Mosquito & & $3-6$ \\
\hline & Dengue HF & Asia, Americas, Africa & Mosquito & & $\begin{array}{l}\text { Unknown for dengue HF, } \\
\text { but } 3-5 \text { for uncomplicated } \\
\text { dengue }\end{array}$ \\
\hline \multirow[t]{2}{*}{ (Tick-borne) } & Kyasanur Forest disease & India & Tick & & $3-8$ \\
\hline & Omsk HF & Soviet Union & Tick & $\begin{array}{l}\text { Muskrat-contaminated } \\
\text { water }\end{array}$ & $3-8$ \\
\hline
\end{tabular}

Abbreviations: HF, hemorrhagic fever; HFRS, hemorrhagic fever with renal syndrome.

Jahrling P. Viral hemorrhagic fevers. In: Textbook of military medicine, Volume 1. Falls Church (VA): Office of the Surgeon General; 1989. 
for transmission by fine particle aerosol. The potential for droplet or aerosol spread of these viruses has been largely responsible for intense academic and military interest in these agents. The Working Group on Civilian Biodefense recently published an analysis of the potential of VHF agents for use as a bioterrorist weapon [3]. They emphasize the great infectivity, ease of transmission, risk to public health, and high mortality associated with these infectious agents as reasons for their biological weapon potential.

Hemorrhagic fever viruses have been weaponized by the former Soviet Union and the United States as part of previous biological weapon programs but no confirmed use of these agents has been reported [4]. Dr. Ken Alibek, the former deputy director of the once-massive Soviet bioweapons program, Biopreparat, claims Soviet scientists successfully had produced a stable Marburg virus biological weapon that could be delivered as an aerosol [5]. Hemorrhagic fever viruses have also been of interest to terrorist groups. Aum Shinrikyo, the Japanese religious cult behind the 1995 Tokyo subway sarin gas attacks [6], sent members to Africa in 1992 to obtain samples of Ebola virus for use in a bioweapon, but was unsuccessful in securing the virus [7].

\section{Mechanism of toxicity}

The use of VHF agents as a biological weapon has been the subject of avid speculation in the popular media and dramatized in books and film by showing a panicked populace in the throes of a rapidly spreading epidemic. The reality is likely to be far less cinematic, although public perceptions of the risk may lead to significant social and economic disruption. The most likely method for spread of VHF is by fine-droplet aerosol, although contamination of surfaces, food, and water are other potential sources of infection. A terrorist group equipped with a sufficient supply of a highly contagious VHF agent, such as Ebola or Marburg, in an environmentally stable form, could cause a mass casualty event with high morbidity and mortality. Multiple studies in nonhuman primates have documented the aerosol spread of Ebola virus [8-10], and droplet spread has been suspected as a mode of disease transmission among infected humans; although, human-to-human aerosol transmission appears to be rare [11].

Although species in the family of filoviruses, such as Ebola and Marburg, likely represent the greatest bioterrorism threat, other VHF agents are also transmissible by droplet spread. Aerosol transmission of Lassa virus, a species in the genus arenavirus endemic in western Africa, has been documented in nonhuman primates under laboratory conditions [12]. During a 1969 outbreak in Nigeria, an index patient transmitted Lassa to 16 other patients in the same hospital ward; transmission was thought to be by way of droplet aerosol spread [13]. As with Lassa virus infection, some viruses from the family of arenaviruses, such as Junin, are typically acquired by way of aerosolization of infected rodent excreta, particularly urine [14], but laboratory workers working with these agents have been become infected through inhalation of aerosols [15]. Similar 
laboratory-related aerosol transmission has also been described with yellow fever [16].

The most commonly documented method of filovirus transmission has been by direct contact with blood, body fluids, or tissue of infected persons or nonhuman primates. A recent review of wild animal mortality and human Ebola outbreaks in Gabon and the Republic of Congo concluded that all human Ebola outbreaks in this region from 2001 to 2003 resulted from handling infected wild animal carcasses [17]. Analysis of 21 carcasses revealed that 10 gorillas, 3 chimpanzees, and 1 duiker, a small African deer, were infected with Ebola. The discovery of wild animals infected with Ebola does not establish that these animals are natural filovirus reservoirs. Ebola is rapidly fatal in these animals, suggesting that they are not the natural host [18]. Research into the natural host for Ebola is ongoing, with recent work suggesting that small mammals with little contact with humans, such as bats, may be a natural reservoir for filoviruses such as Ebola and Marburg [19].

During the 2000-2001 Ebola outbreak in Uganda, there were 224 (53\%) deaths from 425 presumptive case patients [11]. Three important means of disease transmission were identified during this outbreak: ritual contact with bodies of deceased patients, intrafamilial transmission, and nosocomial spread. In addition, $14(64 \%)$ of 22 of health care workers involved with the care of patients infected with Ebola were also infected, despite the establishment of isolation wards. Once stricter infection control measures were instituted, disease containment was achieved. The ease of person-to-person transmission of Ebola virus is supported by the presence of Ebola virus in the skin and sweat glands of infected persons, as documented by immunohistochemical assay [20].

Conversely, during the 1999 outbreak of Marburg virus infection in Durba, Republic of Congo, few cases of clear person-to-person transmission could be verified [21]. The causative agent behind an ongoing outbreak of hemorrhagic fever in Angola that began in October 2004 was recently identified as Marburg virus. While epidemiologic studies of this outbreak are still underway, it appears that of the 102 identified cases, 95 have died; 75\% of deaths were children [22]. The route of transmission of this infection is not yet known, although a small number of health care workers have already been infected. The primary mode of initial arenavirus infection is aerosolized rodent excreta, typically urine, as rodents are the natural reservoirs of the arenaviruses. Person-to-person transmission of arenaviruses such as Lassa is - as with filoviruses-primarily via contact with infected blood and body fluids [14,23].

The primary pathologic defect in patients with VHF is that of increased vascular permeability [24,25]. Hemorrhagic fever viruses have an affinity for the vascular system, leading initially to signs such as flushing, conjunctival injection, and petechial hemorrhages, usually associated with fever and myalgias. Later, frank mucous membrane hemorrhage may occur, with accompanying hypotension, shock, and circulatory collapse. The relative severity of the clinical presentation may vary depending on the virus in question, amount, and route of exposure. 
In acute disease, patients are extremely viremic, and messenger RNA (mRNA) evidence of multiple cytokine activation exists [26]. In vitro studies reveal these cytokines lead to shock and increased vascular permeability, the basic pathophysiologic processes most often seen in VHF infection [27]. Another prominent pathologic feature is pronounced macrophage involvement [28]. Inadequate or delayed immune response to these novel viral antigens may lead to rapid development of overwhelming viremia. Extensive infection and necrosis of affected organs also are described. Hemorrhagic complications are multifactorial and are related to hepatic damage, consumptive coagulopathy, and primary marrow injury to megakaryocytes. The increased vascular permeability in VHF infection is thought to be secondary to endothelial injury by immunologic factors rather than direct virally mediated endothelial injury. Direct damage to endothelial cells caused by viral-induced cytolysis is not described as the cause of bleeding diathesis in Ebola virus infection [29]. Multisystem organ failure affecting the hematopoietic, neurologic, and pulmonary systems often accompanies the vascular involvement. Hepatic involvement varies with the infecting organism and is at times seen with Ebola, Marburg, as well as other VHF agents, such as yellow fever. Renal failure with oliguria, although a prominent feature of hemorrhagic fever with renal syndrome (HFRS) seen in Hantavirus infection [30], may be seen in other VHF infections as intravascular volume depletion becomes more pronounced. Bleeding complications are particularly prominent with Ebola, Marburg, and the South American arenaviruses.

\section{Clinical presentation}

Although data exist from laboratory-based VHF infection in animal models, most clinical information regarding VHF infection comes from naturally occurring outbreaks. Suspicion for VHF infection in areas where these viruses are endemic should be high for patients who present even with nonspecific symptoms of viral infection, such as high fever, headache, fatigue, myalgias, abdominal pain, and non-bloody diarrhea. This constellation of symptoms has been well described during the initial prodromal period of VHF infection [3]. Following the terrorist incidents in September 2001, the CDC released instructions for recognizing illness associated with the release of a biologic agent, and listed clinical findings associated with Marburg and Ebola virus infection such as abrupt onset of fever, headache, and myalgias, followed by nausea, vomiting, abdominal pain, chest pain, and macular-papular rash, particularly involving the trunk [31]. Although this clinical presentation may not raise the specter of VHF infection in a routine emergency department setting in the United States or Europe, several recent cases of imported VHF infection from endemic areas to industrialized countries have been reported [32-34]. The ease and rapidity of global travel has likely increased the spread of unusual pathogens, including VHF agents. 
In August 2004, a businessman who had made several recent trips to Liberia and Sierra Leone in West Africa presented to a New Jersey emergency department with fever of $103.6^{\circ} \mathrm{F}\left(39.8^{\circ} \mathrm{C}\right)$, chills, sore throat, diarrhea, and back pain. His condition deteriorated rapidly during hospitalization, requiring intubation, and mechanical ventilation. Diagnoses considered included yellow fever and Lassa fever, as well as typhoid fever and malaria. Despite aggressive supportive therapy, the patient died. Postmortem examination confirmed the diagnosis of Lassa fever by serum antigen detection, viral culture, and reverse transcriptase polymerase chain reaction (RT-PCR) assay. None of the patient's identified contacts either within the hospital or before his hospitalization reported symptoms consistent with Lassa virus infection [34].

The incubation period for VHF agents ranges from 2 to 21 days. The nonspecific prodromal symptoms of VHF infection noted above are often variable and differ between VHF agents as well. Filoviruses, such as Ebola and Marburg, tend to have a more rapid onset of symptoms; arenavirus infection may have a slower progression [3]. Because the target of VHF infection is the vascular system, symptoms of endothelial damage and increased vascular permeability tend to predominate. In early infection, patients present with conjunctival injection, mild hypotension, flushing, and petechial rash; in later stages of the disease, frank mucous membrane hemorrhage with shock and generalized bleeding may occur. Involvement of neurologic, pulmonary, and hematopoietic systems may also occur [35]. In Lassa fever, hemorrhagic complications tend to be less common than in filovirus infection. Deafness is a common long-term complication of significant Lassa fever infection. Evidence of hepatic injury such as jaundice is seen in Ebola, Marburg, and yellow fever.

Morbidity and mortality associated with VHF infection can be highly variable. During the 1995 Ebola (strain: Ebola-Zaire) outbreak in Kikwit, Democratic Republic of Congo, the case fatality rate was 81\% [36]. During the 2000-2001 Uganda outbreak, the case fatality rate was just above $50 \%$. The strain of Ebola isolated during the Uganda outbreak was Ebola-Sudan, one of four Ebola subtypes previously described. The others include the most virulent, Ebola-Zaire, with case fatality rates of $80 \%-90 \%$, Ebola-Cote D'Ivoire, and Ebola-Reston (a variant first described in 1989 in Reston, Virginia, that only appears to affect nonhuman primates) [24].

Arenavirus infection typically results in mortality rates of $15 \%-20 \%$ for Lassa fever and 15\%-30\% for the New World arenaviruses [14,37]. Most patients $(80 \%)$ with Lassa fever have either mild or no observable symptoms, and severe disease occurs in only $20 \%$ of those infected [38]. The mode of VHF exposure has been correlated with degree of illness. Particularly in filovirus infection, percutaneous acquisition of the disease is strongly correlated with increased mortality. During the 1976 Ebola-Zaire outbreak, every case of infection caused by contaminated syringes resulted in death [39].

In an African or South American health care setting, the diagnosis of VHF infection is far more likely than in an industrialized nation. Because of the infrequency of VHF illness in industrialized countries, the initial evaluation of a 
patient with suspected imported VHF infection should not only attempt to provide supportive therapy or specific antiviral agents as appropriate, but also to rule out other, more common, pathogens that may have specific therapies. The differential diagnosis of VHF encompasses a wide array of both infectious and non-infectious etiologies. Viral and bacterial illnesses that may mimic VHF include influenza, viral hepatitis, staphylococcal or gram-negative sepsis, meningococcemia, salmonellosis and shigellosis, as well as less common infections such as leptospirosis, malaria, rickettsial diseases (such as Rocky Mountain spotted fever), dengue, and hantavirus. Non-infectious causes that can cause bleeding diathesis include disseminated intravascular coagulation (DIC), idiopathic or thrombotic thrombocytopenic purpura, hemolytic-uremic syndrome, acute leukemia, and collagenvascular diseases [3].

Potentially significant delays in the diagnosis of VHF infection are likely related to the rarity of these infections in the setting of routine emergency department or ICU care. In naturally occurring cases of VHF infection, patients generally have a history of travel to locales where VHF infection is endemic such as West or Central Africa, or South America, or have had contact with infected people or animals, or arthropod vectors, as in yellow fever. In the case of a bioterrorist attack, no warning would likely be forthcoming and the presentation of numbers of febrile patients with various nonspecific constitutional symptoms would be difficult to link to a common infectious source. During the 2001 anthrax bioterrorism attack, a shared route of exposure served to identify infected individuals as well as those who were potentially at risk for infection [40]. The virulence of these infectious agents and the special containment procedures required to handle them safely can introduce significant delays in definitive diagnosis. Hospital microbiology laboratories and local public health facilities are not equipped to diagnose VHF infection, and samples must be sent to either the Centers for Disease Control and Prevention (Atlanta, Georgia) or the US Army Medical Research Institute of Infectious Diseases (USAMRIID; Frederick, Maryland).

In the event of a bioterrorist attack involving large numbers of infected patients, a triage system would have to be enacted to allocate available health care resources to meet patient demand. Because of the rapid progression of disease, particularly in patients with filovirus infection, it has been difficult to establish which patients have the greatest chance for survival. Following an average incubation time of 5-7 days for Ebola or Marburg infection, the onset of disease is rapid; death usually occurs within 6-9 days of the onset of illness [41]. During the 2000-2001 Ebola outbreak in Uganda, a temporary diagnostic laboratory was established on-site, which was able to perform rapid, next-day, testing for Ebola virus by viral antigen capture ELISA and RT-PCR [42]. A retrospective analysis of the data obtained by this field laboratory also demonstrated that viral load correlated with disease outcome. Viral RNA copy levels in patients who died were 100 times higher than among those who survived the infection. RNA copy levels of $10^{8} / \mathrm{mL}$ or higher were associated with a fatal outcome; the positive predictive value was $>90 \%$. Although somewhat intuitive (ie, patients who demonstrated evidence of overwhelming viremia did worse than 
those who did not), these data suggest some potential guidelines for the management of a mass casualty incident involving VHF infection. VHF patients (at least those with confirmed filovirus infection) with documented evidence of severe viremia are unlikely to benefit from the most aggressive resuscitative measures. Potentially saving these resources for those patients with a better chance of survival may result in improved overall survival among infected patients.

Designed for use in rural health care settings with limited resources, the set of guidelines for the care of VHF patients created jointly by the CDC and the World Health Organization can serve as a model for appropriate patient care that minimizes risk to health care providers and other non-infected persons and

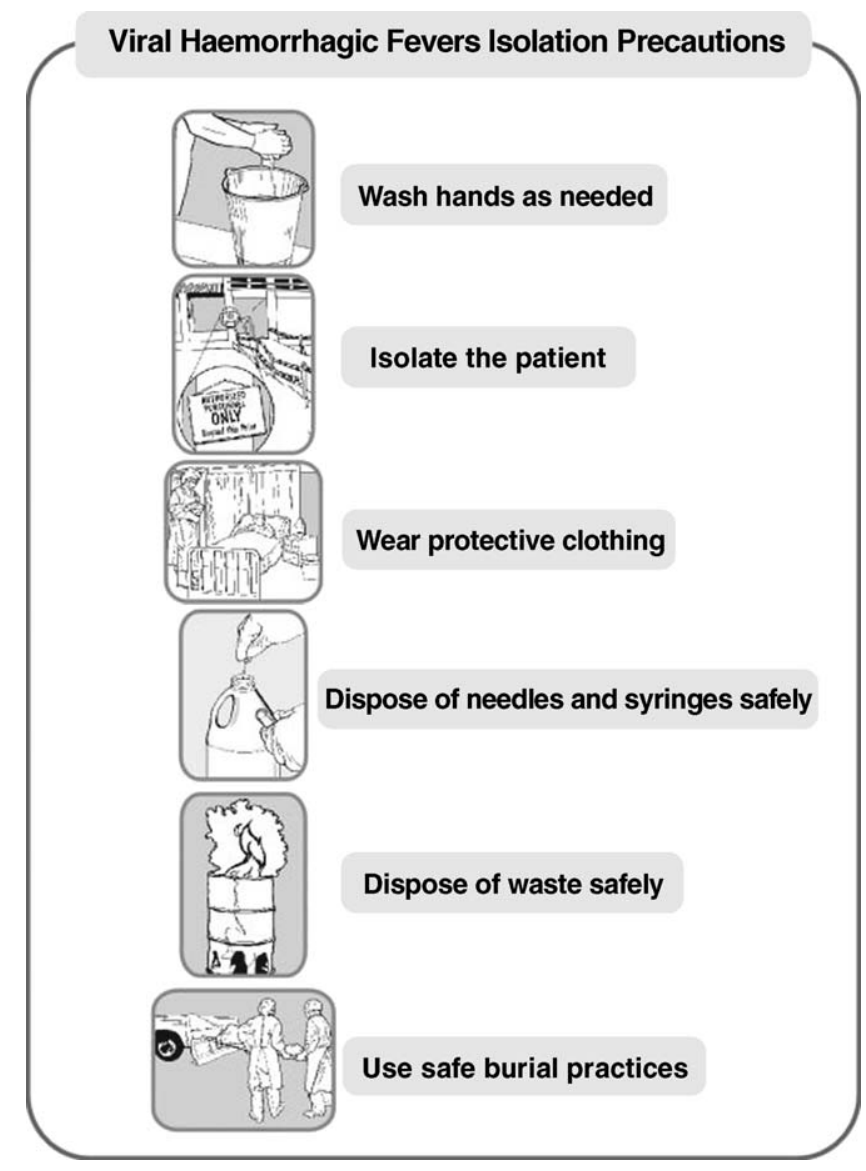

Fig. 1. Viral hemorrhagic fever isolation precautions. This basic set of isolation precautions for patients with suspected or confirmed VHF infection was developed by the CDC and the World Health Organization for instruction of health care providers in Africa. (From Centers for Disease Control and Prevention and World Health Organization. Infection control for viral haemorrhagic fevers in the African health care setting. Atlanta (GA): Centers for Disease Control and Prevention; 1998. Figs. 7, 26; with permission.) 
optimizes use of available resources [43] (Fig. 1). In African filovirus outbreaks, infected patients have been grouped into isolation wards with separate areas for health care personnel to change into protective clothing. In industrialized countries, more resources are typically available and isolation precautions are generally required for only one or two patients. In the setting of a bioterrorism attack involving a VHF agent, however, significant numbers of symptomatic patients may be expected. Because of the potential severity of illness, estimation of the numbers of patients requiring critical care is difficult. Case fatality rates for VHF agents vary from $15 \%$ to as high as $90 \%$, which suggests that the number of infected patients who might require critical care services is likely to represent at least $50 \%$ of symptomatic patients and perhaps nearly all patients with the most virulent forms of filovirus infection.

The need for intensive care for these patients has been clearly demonstrated in recently described cases of imported VHF [34,44]. In 2000, a nurse who was hospitalized with VHF symptoms (and was later diagnosed with Ebola-Zaire) in South Africa developed severe hemorrhagic complications and ultimately died of intracerebral hemorrhage. Before her death, she required prolonged intensive care (including 12 days of mechanical ventilation) as well as significant fluid resuscitation and blood product infusions. She underwent multiple invasive procedures, including two laparotomies, hemodialysis, pulmonary artery catheterization, and vasopressor infusion for persistent hypotension. This patient was cared for at Johannesburg Hospital, in an intensive care unit specifically designated for patients with hemorrhagic fevers. Careful attention to strict barrier precautions was likely responsible for the absence of any further transmission of the illness during the patient's hospitalization $[44,45]$.

\section{Decontamination and isolation}

An essential priority for health care facilities and personnel caring for patients with confirmed or suspected VHF infection is containment of the disease. Both the filoviruses and arenaviruses are highly infectious through direct contact with blood and bodily secretions. Given the risk to health care providers demonstrated during previous naturally occurring VHF outbreaks, institution of appropriate barrier precautions and negative pressure isolation for these patients is vital. During the 1995 Ebola outbreak in Kikwit, Democratic Republic of Congo, 90 (32\%) of 283 infected patients whose occupations were known, were identified as health care workers [46]. The initiation of barrier-nursing precautions during this outbreak was highly effective: only one health care worker became ill after the institution of preventive measures [37] (Fig. 2).

Any suspected case of VHF fever should be reported to the hospital epidemiologist or infection control officer as well as to local and state public health officials. Laboratory directors and personnel should also be notified so that additional precautions can be instituted amongst laboratory personnel. Notification of the CDC is essential in any case of suspected VHF infection to expedite 


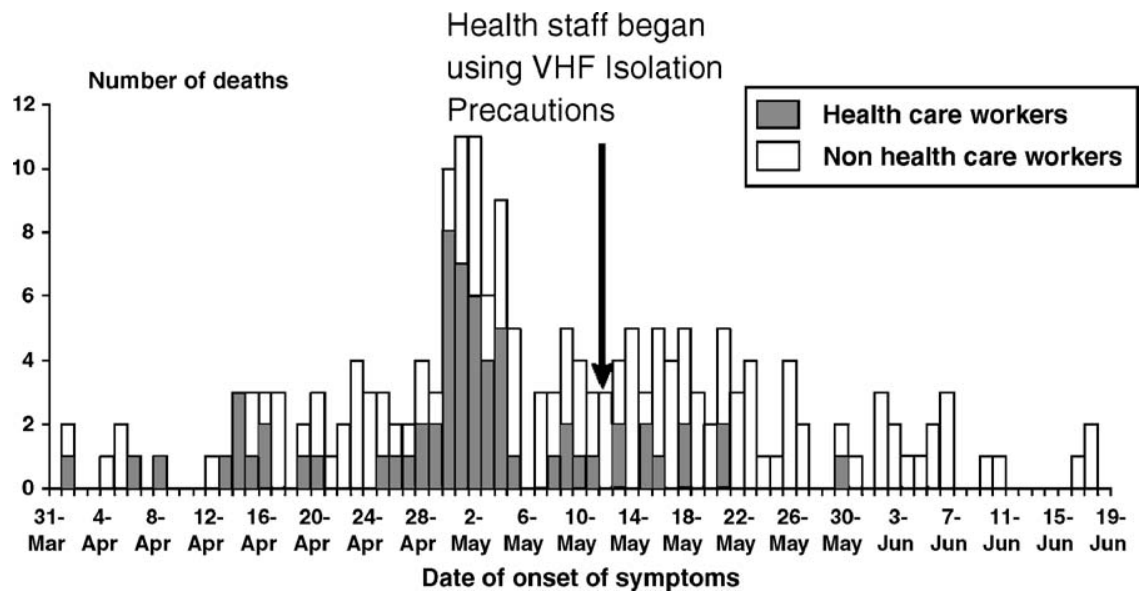

Fig. 2. The number of infected health care workers declined after barrier nursing practices were begun during the Ebola hemorrhagic fever outbreak at Kikwit, Democratic Republic of Congo, 1995. (From Centers for Disease Control and Prevention and World Health Organization. Infection control for viral haemorrhagic fevers in the African health care setting. Atlanta (GA): Centers for Disease Control and Prevention; 1998. Figs. 1, 3; with permission.)

virus-specific diagnostic testing and mobilize appropriate resources for containment and epidemiology [1]. Identification of specific VHF agents is beyond the scope of hospital laboratories and poses substantial risks to laboratory personnel because of the highly infectious nature of these viruses. Even in specialized facilities equipped to handle these agents, accidents have occurred resulting in unintended infection and death $[47,48]$.

Specific infection-control recommendations for care of patients with suspected or confirmed VHF infection include: (1) Strict adherence to hand washing, (2) double gloving and the use of impermeable gowns, (3) N-95 masks or powered air-purifying respirators, (4) negative pressure isolation with 6-12 air exchanges per hour, (5) leg and shoe coverings, and (6) face shields or goggles. Additional containment measures include restricted access by nonessential staff and visitors, dedicated medical equipment for each patient such as stethoscopes, blood pressure cuffs, and if available, point-of-care analyzers, and environmental disinfection with hospital disinfectant approved by the Environmental Protection Agency or 1:100 bleach solution. Multiple potentially infected patients should be placed in the same part of the hospital to minimize exposure to other patients and health care workers. In the event of a mass casualty incident, even large nonpatient-care spaces can be converted into negative pressure areas through the use of portable high-efficiency particulate air filtered forced-air equipment [49]. Multiple studies of infection control measures instituted during VHF outbreaks have documented the efficacy of strict barrier-control measures in markedly reducing or eliminating the risk of disease transmission [14,21,23,32,50-52].

Patients who have survived VHF infection may remain contagious for extended periods of time during convalescence. Semen samples of Ebola survivors have 
demonstrated evidence of Ebola virus by RT-PCR 90 days after disease onset, although no live virus could be isolated [53]. Patients who have died of VHF infection should be promptly cremated or buried. Any unnecessary contact with the corpse including autopsy or embalming should be avoided. All contacts of patients diagnosed with VHF infection, including hospital personnel and laboratory workers, should be placed under medical surveillance for signs of VHF infection for 21 days (the theoretical maximal incubation period for VHF infection) [1,34].

\section{Diagnostic studies}

Hospital laboratories at major academic medical centers lack the capability to safely handle VHF agents. Patient samples must be specially handed and packaged for shippment to authorized laboratories for analysis. Only USAMRIID and CDC currently have the Biosafety Level-4 (BSL-4) laboratory resources to make virus-specific diagnoses of VHF infection [1]. The increased demand for BSL-4 containment facilities for bioterrorism research has recently led to a planned expansion of BLS-3 and BSL-4 facilities, including two new BSL-4rated National Biocontainment Laboratories at Boston University and the University of Texas Medical Branch in Galveston, both funded by the National Institutes of Health [54].

Because of the barriers inherent in virus-specific testing, a case definition of presumptive VHF infection has been developed in the setting of naturally occurring VHF outbreaks using specific clinical diagnostic criteria (Box 1). The case definition developed for Ebola virus infection after the 1995 Kikwit outbreak uses the presence of fever and visible signs of bleeding, such as bleeding from gums, nose, conjunctival hemorrhage, ecchymosis, hematochezia, melena or hematemesis [43]. Other criteria include fever, with or without signs of bleeding, for persons who have contact with a patient with suspected Ebola virus infection. A clear, concise case definition for suspected VHF infection can serve as an appropriate initial screening tool in the setting of suspected VHF outbreak such as might be caused by an act of bioterrorism. In such a scenario, the large volume of patient specimens requiring definitive viral identification would likely be labor intensive and time consuming, potentially resulting in significant delays in diagnosis.

In specialized laboratories, virus-specific diagnoses of VHF agents can be made using several methods, including viral antigen-capture ELISA, RT-PCR, and viral isolation [3]. During the 1995 Kikwit Ebola outbreak, CDC researchers used viral antigen-capture ELISA assays as well as immunohistochemical staining of formalin-fixed tissue samples using a specific polyclonal antibody [46]. In recent filovirus outbreaks, field laboratories capable of performing viral antigencapture ELISA as well as RT-PCR have been established to allow health care personnel access to highly specific diagnostic assays without substantial delays in specimen processing [42]. The use of a largely automated portable thermal cycler to prepare biological samples for DNA or RNA RT-PCR identification 


\section{Box 1. Case Definition, Ebola Hemorrhagic Fever (EHF)}

Anyone presenting with fever and signs of bleeding such as:

- Bleeding of the gums

- Bleeding from the nose

- Red eyes

- Bleeding into the skin (purple colored patches in the skin)

- Bloody or dark stools

- Vomiting blood

- Other unexplained signs of bleeding

Whether or not there is a history of contact with a suspected case of EHF.

OR

Anyone living or deceased with:

- Contact with a suspected case of EHF AND

- A history of fever, with or without signs of bleeding.

OR

Anyone living or deceased with a history of fever AND 3 of the following symptoms:

- Headache

- Vomiting

- Loss of appetite

- Diarrhea

- Weakness or severe fatigue

- Abdominal pain

- Generalized muscle or joint pain

- Difficulty swallowing

- Difficulty breathing

- Hiccups

OR

Any unexplained death in an area with suspected cases of EHF.

(From Centers for Disease Control and Prevention and World Health Organization. Infection control for viral haemorrhagic fevers in the African health care setting. Atlanta (GA): Centers for Disease Control and Prevention; 1998. p. 145; with permission.) 
has reduced potentially hazardous exposure by laboratory personnel to highly infectious biological agents [55,56].

For the diagnosis of Lassa fever, ELISA assays have recently proved as reliable as indirect fluorescent antibody testing, the previous standard method of viral identification [57]. Junin virus, the cause of Argentine hemorrhagic fever, has been identified using ELISA assays to detect Junin IgG antibodies in infected rodents [58]. More recently, PCR assays have become available for both Lassa and Junin, and a PCR has been developed that predictably amplifies any member of the Arenaviridae family by targeting a highly conserved RNA terminal segment [59].

\section{Treatment}

Treatment for VHF infection is primarily supportive. There are no antiviral drugs approved by the US Food and Drug Administration for use in the setting of VHF infection [3]; however, small published trials have shown that intravenous ribavirin, a nucleoside analog that markedly reduces levels of guanosine monophosphate, guanosine diphosphate, and guanosine triphosphate, has been used to treat Lassa fever with significant reduction in mortality [60]. Similar results have been shown using intravenous ribavirin for the treatment of some New World arenaviruses as well [61]. Ribavirin is available for compassionate use under an investigational new drug protocol.

No antiviral agents have proven effective against either Ebola or Marburg infection and development of a filovirus virus vaccine has been a significant focus of ongoing research efforts [62-65]. An Ebola DNA plasmid vaccine that relies on a DNA "primer" from three strains of Ebola virus recently completed NIH-sponsored Phase I human trials, and is in an active follow-up phase, however, no data are yet available $[66,67]$. Another team of researchers is currently focusing on an Ebola vaccine based on non-virulent Ebola virus proteins that stimulate both antibody- and T cell-mediated host immune responses [68]. This group has also described similar protection from Marburg virus infection using Marburg virus-like particles [69]. The Ebola protein-based vaccine is currently undergoing primate studies. The efficacy of an Ebola vaccine in humans will be understandably difficult to assess clinically given the unlikely scenario that healthy human volunteers would consent to being exposed to live wild-type Ebola virus, even if vaccinated [70].

Research into vaccines against Lassa virus and other New World arenaviruses are ongoing at CDC [71]. Although additional funding has recently become available for Lassa virus research, difficulty in conducting vaccine trials in endemic areas and lack of political stability in these regions remain significant obstacles to vaccine development and testing. A live attenuated virus vaccine against Argentine hemorrhagic fever (Junin) is available and effective, and may protect against Bolivian hemorrhagic fever (caused by Machupo virus) as well $[34,72]$. 
In the setting of a bioterrorist attack using a VHF bioweapon, vaccination is not a viable solution. Following vaccination, antibody titers tend to rise slowly, typically requiring months to confer full immunity. Treatment of persons already infected with VHF agents has been the subject of intense research interest, particularly given the increasing number of recent, naturally occurring filovirus outbreaks. The use of convalescent serum (ie, sera from patients who have survived infection) has been suggested as a possible therapy. Late during the 1995 Kikwit outbreak, eight Ebola patients received whole blood transfusions from Ebola survivors. Of these, seven survived. However, there is no clear evidence that links their survival directly to this therapy, and no clear demonstration of benefit can be generalized from these data [73]. The use of immune plasma has proved effective in the treatment of some arenaviruses, including Junin and Machupo, although difficulties with plasma collection and storage may limit the effectiveness of this therapy [74,75].

Novel antiviral regimens have had some success in in vitro studies against Lassa, Ebola and the Severe Acute Respiratory Syndrome (SARS) coronavirus [76]. In addition to blocking viral replication, recent efforts have attempted to target the VHF disease process itself by inhibiting the action of proinflammatory cytokines thereby attenuating the consumptive coagulopathy that is the hallmark of the disease [77]. Currently, however, there is no effective therapy for VHF infection other than ribavirin for patients with Lassa fever or New World arenavirus infection; treatment for filovirus infection remains supportive.

\section{Supportive care}

Treatment of the VHF-infected patient presents substantial difficulties, which are complicated by the need to maintain strict barrier controls to prevent the transmission of VHF infection to treating health care and laboratory personnel, The need to administer fluids, electrolytes, and blood products is likely to be significant in these patients. In patients with Lassa fever, dehydration, edema, hypotension, and renal insufficiency are common [38]. The use of invasive procedures, however, should be minimized to reduce the risk to staff of iatrogenic transmission of a potentially lethal pathogen. In published descriptions of imported cases of VHF infection, the time to diagnosis is often significantly delayed. After returning from Sierra Leone in West Africa, a surgeon was hospitalized in the Netherlands with a working diagnosis of typhoid fever, and was not diagnosed with Lassa fever until day 13 and died 3 days later despite the initiation of ribavirin therapy [23]. After diagnosis, 128 unprotected contacts were identified; of the 83 investigated contacts, none showed seroconversion by Lassa virus antibody screen. Although the diagnosis in this case was delayed, methicillin-resistant Staphylococcus aureus (MRSA) contact isolation precautions had been instituted early during the patient's hospitalization.

The need for volume resuscitation in patients with VHF infection is greatest in late stages of infection, as patients develop worsening hemorrhage and shock. 
It has been shown that viral loads also tend to be higher in later stages of infection, which may increase infectivity of blood or body fluids [42]. Despite the intuitive concept that the sickest patients may benefit the most from the highest level of care, there is no clear evidence that more vigorous resuscitation of severely symptomatic VHF patients leads to a decrease in mortality. During the Kikwit Ebola outbreak, however, an increased incidence of coughing and hemoptysis among survivors was thought perhaps to reflect increased use of parenteral fluid resuscitation later during the outbreak [78]. The data available regarding the care of VHF patients in modern emergency department and intensive care unit settings are confined to a few isolated case reports from which no clear generalization regarding improvement in patient outcomes can be derived. In recent naturally-occurring outbreaks of Ebola or Marburg virus, most of the patients were cared for in isolation wards, grouped together with similarly infected patients because of lack of individualized isolation, decontamination, and treatment facilities.

\section{Clinical course and prognostic factors}

A typical clinical course for patients with VHF infection cannot be generalized for all VHF patients as the causative organism is closely linked to the patient's clinical course and overall outcome. Some VHF agents, such as the arenaviruses, have a relatively low incidence of hemorrhagic side effects; others, such as Ebola and Marburg, tend to follow a more fulminant course. As previously noted, most patients with Lassa fever tend to have a mild clinical course, and those infected with Ebola-Zaire may experience a case fatality rate of $80 \%-90 \%[38,46]$.

The presence of significant volume depletion, coupled with hemodynamic instability is a poor prognostic sign in patients with VHF infection. In the largest case study of Ebola-Zaire infection, terminally ill patients typically presented with signs of severe volume loss, including obtundation, anuria, and shock [78]. Another finding noted in this case series was the premorbid finding of tachypnea. Among this group of patients, tachypnea was the most significant criteria differentiating between fatal and nonfatal outcomes $(P=0.0027)$ [78]. Tachypnea was generally associated with bleeding from mucosa and puncture sites, anuria and hiccups; the tachypnea preceded death by only a few days.

Prognostic factors associated with worse patient outcomes have also been derived from field-based genetic studies of VHF agents, as well as the presence or absence of certain clinical signs or symptoms. RT-PCR assays and quantitative analysis of RNA viral load in patients infected with Ebola-Sudan during the 2000-2001 Uganda outbreak were used retrospectively to identify those patients more likely to have a fatal outcome [42]. The presence of edema (typically accompanied by dehydration and hypotension) has been identified as a poor prognostic sign in patients with Lassa fever [38]. A review of pediatric Lassa fever cases identified a "swollen baby syndrome" consisting of widespread edema, abdominal distension, and bleeding that ended in death in three of four 
cases. Its absence is thought to be a good prognostic factor in children with Lassa fever [79].

Unfortunately, the largest clinical studies of VHF patients have been derived from an imperfect combination of highly sensitive laboratory-based viral assays, and unreliable or incomplete clinical data obtained during naturally occurring outbreaks in rural Third World health care settings. These complex interdependent factors complicate the development of rigorous, evidence-based conclusions regarding the expected clinical course or prognostic factors for VHF patients in an urban, industrialized hospital setting where state-of-the-art emergency department and intensive care resources are readily available.

\section{Summary}

The previously unthinkable prospect of bioterrorism has become, in the post September 11 political climate, a proven threat that presents a substantial, ongoing risk to industrialized nations. This risk requires a healthy respect for the capabilities of the most lethal potential agents of bioterrorism, in this case, the viral hemorrhagic fevers. These lethal viruses represent a continuing public health threat in endemic areas. Now, because of the ease and speed of global travel, business travelers and tourists unwittingly infected with these deadly pathogens are arriving without warning at hospitals in industrialized nations, presenting novel diagnostic challenges - as well as significant new risksto western health care workers and hospital employees. By recognizing risk factors for both naturally acquired VHF infection as well as signs and symptoms of a VHF-based bioterrorism attack, physicians and other health care workers who use proper barrier precautions can evaluate and manage patients suspected of harboring VHF infection and at the same time minimize the infectious risk of these highly contagious and potentially lethal pathogens.

\section{References}

[1] Centers for Disease Control and Prevention. Update: management of patients with suspected viral hemorrhagic fever - United States. MMWR Morb Mortal Wkly Rep 1995;44(25):475-9.

[2] Centers for Disease Control and Prevention. Biological and chemical terrorism: strategic plan for preparedness and response. Recommendations of the CDC Strategic Planning Workgroup. MMWR Recomm Rep 2000 Apr 21;49(RR-4):1-14.

[3] Borio L, Inglesby T, Peters CJ, et al. Hemorrhagic fever viruses as biological weapons: medical and public health management. JAMA 2002;287(18):2391-405.

[4] Davis CJ. Nuclear blindness: An overview of the biological weapons programs of the former Soviet Union and Iraq. Emerg Infect Dis 1999;5(4):509-12.

[5] Alibek K, Handelman S. Biohazard: the chilling true story of the largest covert biological weapons program in the world, told from the inside by the man who ran it. New York: Random House; 1999.

[6] Okumura T, Suzuki K, Fukuda A, et al. The Tokyo subway sarin attack: disaster management, Part 1: community emergency response. Acad Emerg Med 1998;5(6):613-7. 
[7] Global Proliferation of Weapons of Mass Destruction. Hearings Before the Permanent Subcommittee on Investigations of the Committee on Governmental Affairs, United States Senate, $104^{\text {th }}$ Cong, $1^{\text {st }}-2^{\text {nd }}$ Sess (1996).

[8] Jaax N, Jahrling P, Geisbert T, et al. Transmission of Ebola virus (Zaire strain) to uninfected control monkeys in a biocontainment laboratory. Lancet 1995;346(8991-8992):1669-71.

[9] Johnson E, Jaax N, White J, et al. Lethal experimental infections of rhesus monkeys by aerosolized Ebola virus. Int J Exp Pathol 1995;76(4):227-36.

[10] Leffel EK, Reed DS. Marburg and Ebola viruses as aerosol threats. Biosecur Bioterror 2004; 2(3):186-91.

[11] Centers for Disease Control and Prevention. Outbreak of Ebola hemorrhagic fever Uganda, August 2000-January 2001. MMWR Morb Mortal Wkly Rep 2001;50(5):73-7.

[12] Stephenson EH, Larson EW, Dominik JW. Effect of environmental factors on aerosol-induced Lassa virus infection. J Med Virol 1984;14(4):295-303.

[13] Carey DE, Kemp GE, White HA, et al. Lassa fever. Epidemiological aspects of the 1970 epidemic, Jos, Nigeria. Trans R Soc Trop Med Hyg 1972;66(3):402-8.

[14] Charrel RN, de Lamballerie X. Arenaviruses other than Lassa virus. Antiviral Res 2003; 57(1-2):89-100.

[15] Lehmann-Grube F. Portraits of viruses: arenaviruses. Intervirology 1984;22(3):121-45.

[16] Banerjee K, Gupta NP, Goverdhan MK. Viral infections in laboratory personnel. Indian J Med Res 1979;69:363-73.

[17] Rouquet P, Froment J-M, Bermejo M, et al. Wild animal mortality monitoring and human Ebola outbreaks, Gabon and Republic of Congo, 2001-2003. Emerg Infect Dis 2005;11(2): $283-90$.

[18] Centers for Disease Control and Prevention. Update: filovirus infection associated with contact with nonhuman primates or their tissues. MMWR Morb Mortal Wkly Rep 1990;39(24):404-5.

[19] Peterson AT, Carroll DS, Mills JN, et al. Potential mammalian filovirus reservoirs. Emerg Infect Dis 2004;10(12):2073-81.

[20] Zaki SR, Shieh WJ, Greer PW, et al. A novel immunohistochemical assay for the detection of Ebola virus in skin: implications for diagnosis, spread, and surveillance of Ebola hemorrhagic fever. Commission de Lutte contre les Epidemies a Kikwit. J Infect Dis 1999;179(Suppl 1): S36-47.

[21] Colebunders R, Sleurs H, Pirard P, et al. Organisation of health care during an outbreak of Marburg haemorrhagic fever in the Democratic Republic of Congo, 1999. J Infect 2004; 48(4):347-53.

[22] International Society for Infectious Diseases. Hemorrhagic fever- Angola: Marburg virus confirmed, March 22, 2005 [Archive no. 20050322.0831]. Available at: http://www.promedmail. org. Accessed March 10, 2005.

[23] Swaan CM, van den Broek PJ, Kampert E, et al. Management of a patient with Lassa fever to prevent transmission. J Hosp Infect 2003;55(3):234-5.

[24] Peters CJ, LeDuc JW. An introduction to Ebola: the virus and the disease. J Infect Dis 1999;179(Suppl 1):ix-xvi.

[25] Peters CJ, Zaki SR. Role of the endothelium in viral hemorrhagic fevers. Crit Care Med 2002;30(5 Suppl):S268-73.

[26] Villinger F, Rollin PE, Brar SS, et al. Markedly elevated levels of interferon (IFN)-gamma, IFN-alpha, interleukin (IL)-2, IL-10, and tumor necrosis factor-alpha associated with fatal Ebola virus infection. J Infect Dis 1999;179(Suppl 1):S188-91.

[27] Feldmann H, Bugany H, Mahner F, et al. Filovirus-induced endothelial leakage triggered by infected monocytes/macrophages. J Virol 1996;70(4):2208-14.

[28] Geisbert TW, Hensley LE, Larsen T, et al. Pathogenesis of Ebola hemorrhagic fever in cynomolgus macaques: evidence that dendritic cells are early and sustained targets of infection. Am J Pathol 2003;163(6):2347-70.

[29] Geisbert TW, Young HA, Jahrling PB, et al. Pathogenesis of Ebola hemorrhagic fever in primate models: evidence that hemorrhage is not a direct effect of virus-induced cytolysis of endothelial cells. Am J Pathol 2003;163(6):2371-82. 
[30] Lee HW. Hemorrhagic fever with renal syndrome in Korea. Rev Infect Dis 1989;11 (May-Jun):S864-76.

[31] Centers for Disease Control and Prevention. Recognition of illness associated with the intentional release of a biologic agent. MMWR Morb Mortal Wkly Rep 2001;50(41):893-7.

[32] Haas WH, Breuer T, Pfaff G, et al. Imported Lassa fever in Germany: surveillance and management of contact persons. Clin Infect Dis 2003;36(10):1254-8.

[33] Hugonnet S, Sax H, Pittet D. Management of viral haemorrhagic fevers in Switzerland. Euro Surveill 2002;7(3):42-4.

[34] Centers for Disease Control and Prevention (CDC). Imported Lassa fever-New Jersey, 2004. MMWR Morb Mortal Wkly Rep 2004;53(38):894-7.

[35] Jahrling P. Viral hemorrhagic fevers. In: Zajtchuk R, Bellamy RF, editors. Textbook of military medicine: medical aspects of chemical and biological warfare. Chapter 29. Washington DC: Office of the Surgeon General; 1989. p. 591-602.

[36] Khan AS, Tshioko FK, Heymann DL, et al. The reemergence of Ebola hemorrhagic fever, Democratic Republic of the Congo, 1995. Commission de Lutte contre les Epidemies a Kikwit. J Infect Dis 1999;179(Suppl 1):S76-86.

[37] McCormick JB, King IJ, Webb PA, et al. A case-control study of the clinical diagnosis and course of Lassa fever. J Infect Dis 1987;155(3):445-55.

[38] Richmond JK, Baglole DJ. Lassa fever: epidemiology, clinical features, and social consequences. BMJ 2003;327(7426):1271-5.

[39] World Health Organization. Ebola haemorrhagic fever in Zaire, 1976. Bull World Health Organ 1978;56(2):271-93.

[40] Centers for Disease Control and Prevention. Update: investigation of bioterrorism-related anthrax and adverse events from antimicrobial prophylaxis. MMWR Morb Mortal Wkly Rep 2001;50(44):973-6.

[41] Bray M. Defense against filoviruses used as biological weapons. Antiviral Res 2003;57(1-2): $53-60$.

[42] Towner JS, Rollin PE, Bausch DG, et al. Rapid diagnosis of Ebola hemorrhagic fever by reverse transcription-PCR in an outbreak setting and assessment of patient viral load as a predictor of outcome. J Virol 2004;78(8):4330-41.

[43] Centers for Disease Control and Prevention, World Health Organization. Infection control for viral haemorrhagic fevers in the African health care setting. Atlanta (GA): Centers for Disease Control and Prevention; 1998. p. 1-198.

[44] Richards GA, Murphy S, Jobson R, et al. Unexpected Ebola virus in a tertiary setting: clinical and epidemiologic aspects. Crit Care Med 2000;28(1):240-4.

[45] Gradon J. An outbreak of Ebola virus: lessons for everyday activities in the intensive care unit. Crit Care Med 2000;28(1):284-5.

[46] Centers for Disease Control and Prevention. Update: outbreak of Ebola viral hemorrhagic fever-Zaire, 1995. MMWR Morb Mortal Wkly Rep 1995;44(25):468-9, 475.

[47] Barry M, Russi M, Armstrong L, et al. Brief report: treatment of a laboratory-acquired Sabia virus infection. N Engl J Med 1995;333(5):294-6.

[48] International Society for Infectious Diseases. Ebola, lab accident death - Russia (Siberia), May 22, 2004. [Archive no. 20040522.1377]. Available at: http://www.promedmail.org. Accessed March 10, 2005.

[49] Rosenbaum RA, Benyo JS, O'Connor RE, et al. Use of a portable forced air system to convert existing hospital space into a mass casualty isolation area. Ann Emerg Med 2004;44(6):628-34.

[50] Crowcroft NS, Meltzer M, Evans M, et al. The public health response to a case of Lassa fever in London in 2000. J Infect 2004;48(3):221-8.

[51] Communicable Disease Surveillance Centre. Lassa fever imported to England. Commun Dis Rep CDR Wkly 2000;10(11):99.

[52] Lamunu M, Lutwama JJ, Kamugisha J, et al. Containing a haemorrhagic fever epidemic: the Ebola experience in Uganda (October 2000-January 2001). Int J Infect Dis 2004;8(1):27-37.

[53] Rowe AK, Bertolli J, Khan AS, et al. Clinical, virologic, and immunologic follow-up of convalescent Ebola hemorrhagic fever patients and their household contacts, Kikwit, Demo- 
cratic Republic of the Congo. Commission de Lutte contre les Epidemies a Kikwit. J Infect Dis 1999;179(Suppl 1):S28-35.

[54] NIAID funds construction of biosafety laboratories. Available at http://www.nih.gov/news/pr/ sep2003/niaid-30.htm. Accessed March 10, 2005.

[55] Weidmann M, Muhlberger E, Hufert FT. Rapid detection protocol for filoviruses. J Clin Virol 2004;30(1):94-9.

[56] Drosten C, Kummerer BM, Schmitz H, et al. Molecular diagnostics of viral hemorrhagic fevers. Antiviral Res 2003;57(1-2):61-87.

[57] Bausch DG, Rollin PE, Demby AH, et al. Diagnosis and clinical virology of Lassa fever as evaluated by enzyme-linked immunosorbent assay, indirect fluorescent-antibody test, and virus isolation. J Clin Microbiol 2000;38(7):2670-7.

[58] Morales MA, Calderon GE, Riera LM, et al. Evaluation of an enzyme-linked immunosorbent assay for detection of antibodies to Junin virus in rodents. J Virol Methods 2002;103(1):57-66.

[59] Gunther S, Emmerich P, Laue T, et al. Imported lassa fever in Germany: molecular characterization of a new lassa virus strain. Emerg Infect Dis 2000;6(5):466-76.

[60] McCormick JB, King IJ, Webb PA, et al. Lassa fever. Effective therapy with ribavirin. N Engl J Med 1986;314(1):20-6.

[61] Enria DA, Maiztegui JI. Antiviral treatment of Argentine hemorrhagic fever. Antiviral Res 1994;23(1):23-31.

[62] Geisbert TW, Hensley LE. Ebola virus: new insights into disease aetiopathology and possible therapeutic interventions. Expert Rev Mol Med 2004;6(20):1-24.

[63] Geisbert TW, Jahrling PB. Towards a vaccine against Ebola virus. Expert Rev Vaccines 2003; 2(6):777-89.

[64] Sullivan NJ, Sanchez A, Rollin PE, et al. Development of a preventive vaccine for Ebola virus infection in primates. Nature 2000;408(6812):605-9.

[65] Hart MK. Vaccine research efforts for filoviruses. Int J Parasitol 2003;33(5-6):583-95.

[66] Vastag B. Ebola vaccines tested in humans, monkeys. JAMA 2004;291(5):549-50.

[67] NIAID Ebola vaccine enters human trial. Available at http://www.niaid.nih.gov/newsroom/ releases/ebolahumantrial.htm. Accessed March 10, 2005.

[68] Warfield KL, Bosio CM, Welcher BC, et al. Ebola virus-like particles protect from lethal Ebola virus infection. Proc Natl Acad Sci USA 2003;100(26):15889-94.

[69] Warfield KL, Swenson DL, Negley DL, et al. Marburg virus-like particles protect guinea pigs from lethal Marburg virus infection. Vaccine 2004;22(25-26):3495-502.

[70] Gibbs WW. An uncertain defense. How do you test that a human Ebola vaccine works? You don't. Sci Am 2004;291(4):20, 24.

[71] Fisher-Hoch SP, McCormick JB. Lassa fever vaccine. Expert Rev Vaccines 2004;3(2):189-97.

[72] Maiztegui JI, McKee Jr KT, Barrera Oro JG, et al. Protective efficacy of a live attenuated vaccine against Argentine hemorrhagic fever. J Infect Dis 1998;177(2):277-83.

[73] Mupapa K, Massamba M, Kibadi K, et al. Treatment of Ebola hemorrhagic fever with blood transfusions from convalescent patients. J Infect Dis 1999;179(Suppl 1):S18-23.

[74] Enria DA, Briggiler AM, Fernandez NJ, et al. Importance of dose of neutralising antibodies in treatment of Argentine haemorrhagic fever with immune plasma. Lancet 1984;2(8397):255-6.

[75] Harrison LH, Halsey NA, McKee Jr KT, et al. Clinical case definitions for Argentine hemorrhagic fever. Clin Infect Dis 1999;28(5):1091-4.

[76] Gunther S, Asper M, Roser C, et al. Application of real-time PCR for testing antiviral compounds against Lassa virus, SARS coronavirus and Ebola virus in vitro. Antiviral Res 2004; 63(3):209-15.

[77] Geisbert TW, Hensley LE, Jahrling PB, et al. Treatment of Ebola virus infection with a recombinant inhibitor of factor VIIa/tissue factor: a study in rhesus monkeys. Lancet 2003; 362(9400):1953-8.

[78] Bwaka MA, Bonnet MJ, Calain P, et al. Ebola hemorrhagic fever in Kikwit, Democratic Republic of the Congo: clinical observations in 103 patients. J Infect Dis 1999;179(Suppl 1):S1-7.

[79] Monson MH, Cole AK, Frame JD, et al. Pediatric Lassa fever: a review of 33 Liberian cases. Am J Trop Med Hyg 1987;36(2):408-15. 